\title{
Acarosis y zoonosis relacionadas
}

\author{
Leonor Jofré M., Isabel Noemí H., Patricia Neira O., Tirza Saavedra U. y Cecilia Díaz L.
}

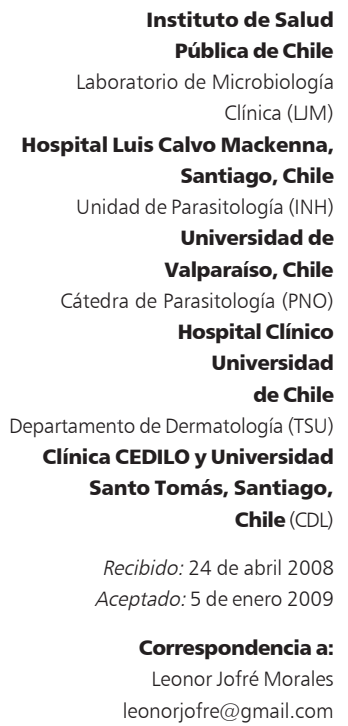

Instituto de Salud

Pública de Chile

Laboratorio de Microbiología

Clínica (UM)

Hospital Luis Calvo Mackenna,

Santiago, Chile

Unidad de Parasitología (INH)

Universidad de

Valparaíso, Chile

Cátedra de Parasitología (PNO)

Hospital Clínico

Universidad

de Chile

Departamento de Dermatología (TSU)

Clínica CEDILO y Universidad

Santo Tomás, Santiago,

Chile (CDL)

Recibido: 24 de abril 2008

Aceptado: 5 de enero 2009

\begin{abstract}
Correspondencia a:
Leonor Jofré Morales
\end{abstract} leonorjofre@gmail.com

$\mathrm{D}$ iferentes especies de ácaros infestan a animales (acariasis) y algunos de ellos causan enfermedad en el hombre (acarosis). Los ácaros pertenecen al phylum Arthropoda, clase Arachnida y subclase Acari. Son de pequeño tamaño, alrededor de 0,2 a $0,4 \mathrm{~mm}$, poseen tres pares de patas en su fase larval y cuatro en el estado de ninfa y adulto.

Más de 30.000 especies han sido descritas en el mundo con numerosos géneros y especies, que pueden ser ectoparásitos y endoparásitos. Varios de estos ácaros tienen importancia médica, especialmente en medicina veterinaria ${ }^{1,2}$.

Se distinguen de los arácnidos por la presencia de gnatosoma y la falta de división entre el abdomen y el cefalotórax. Algunos excavan la piel como Sarcoptes scabiei. Abandonan al hospedero una vez que se alimentan $^{1}$. En el hombre producen una dermatitis con lesiones generalmente papulares, pruriginosas y en ocasiones con reacción alérgica, secundaria a la saliva que se deposita mientras se alimentan ${ }^{3}$.

Los ácaros hematófagos o los que se alimentan de linfa, tienen el potencial de transmitir diversos agentes patógenos virales, bacterianos o parasitarios. Los ácaros de los alimentos y del polvo no son vectores de agentes zoonóticos ${ }^{4,5}$. Las diferentes especies de ácaros zoonóticos y agentes transmitidos se detallan en las Tablas 1 y 2 .

La presente revisión tiene por objetivo contribuir al conocimiento de los principales ácaros de animales de compañía y de otros animales, que se pueden transmitir al hombre en forma accidental. La importancia de algunos de ellos es que son transmisores de agentes infecciosos. El conocimiento de estos agentes permite su sospecha diagnóstica, al considerar los antecedentes epidemiológicos asociados y una toma de decisiones y tratamiento adecuados.

\section{Ácaros de perros y gatos}

\section{Sarna sarcóptica}

El año 1978 Fain demostró la existencia de una especie de la familia Sarcoptidae altamente variable, al analizar algunas de las 30 especies del género. Según el hospedero animal se identifican las siguientes variedades Sarcoptes scabiei var bovis, S. scabiei var suis, S. scabiei var equi, S. scabiei var aucheniae, S. scabiei var cuniculi y S. scabiei var canis que parasitan al ganado bovino, cerdo, caballo, llamas y alpacas, conejos y perros respectivamente . $^{6}$

La sarna producida por el género Sarcoptes se denomina sarna sarcóptica. En perros es producida por Sarcoptes scabiei var canis. Afecta por lo general a animales poco cuidados, mal alimentados y que viven en condiciones de hacinamiento. Es hospedero específico, infesta rara vez a gatos y cuando se presenta, es probable la existencia de una enfermedad subyacente, como la inmunodeficiencia felina. Puede afectar a personas en contacto con mascotas, por lo que es una enfermedad con un alto potencial zoonótico. 
El ácaro adulto de S. scabiei var canis es de forma ovoide, cuerpo no segmentado con cuatro pares de patas cortas. Las hembras tienen casi el doble del tamaño de los machos. El ciclo de vida completo dura 17 a 21 días y se lleva a cabo sobre el perro. La hembra cava túneles en el estrato córneo de la piel y deposita sus huevos ${ }^{7}$ (Figura 1).

La sarna sarcóptica se transmite fácilmente entre los perros por contacto directo. El período de incubación es variable (10 días a 8 semanas), dependiendo del nivel de exposición, parte del cuerpo expuesta y número de ácaros transmitidos. Ocasiona en el animal lesiones papulares intensamente pruriginosas, costras, excoriaciones, inflamación e infección bacteriana secundaria. En el examen físico se aprecia alopecia, eritema ubicado preferentemente en el pabellón auricular, extremidades (codos y axila) y en la parte ventral del abdomen, que de no tratarse se generaliza (Figuras 2 y 3); presenta un reflejo otopedal positivo. Existen portadores asintomáticos de $S$. scabiei var canis $^{6}$.

En el hombre puede introducirse en la epidermis, después de un contacto prolongado con el animal, habitualmente después de dormir con ellos. Aparecen lesiones a las 24 a 96 horas en las áreas de contacto con el perro, de tipo pápulo-eritematosas intensamente pruriginosas ${ }^{7,8}$ (Figura 4). La duración de la sintomatología producida por la variedad canis es habitualmente de unas pocas semanas, aunque puede extenderse a meses; por esta razón se creía que no requería de tratamiento y se manejaba en forma asintomática. Sin embargo, en los últimos años se ha visto pacientes con lesiones persistentes, muy sintomáticas, que ha sido necesario tratar con acaricidas ${ }^{9,10}$. En nuestro medio uno de cada cuatro propietarios de mascotas infestadas se contagia con este agente ${ }^{11}$.

El diagnóstico de sarna sarcóptica se basa en la historia de intenso prurito de aparición súbita, signología clínica y el contacto de otros animales con lesiones, incluyendo al hombre. El diagnóstico es clínico, el ácaro-test resulta negativo la mayoría de las veces, el rendimiento del raspado cutáneo es de $\sim 25 \%{ }^{9}$.

En otros animales la sarna produce un cuadro similar. En el caballo se manifiesta por lesiones que comienzan en la cabeza y cuello, afectan también a la cruz y la región de la montura. El hombre se infesta por andar en pelo y por el estrecho contacto con el animal enfermo o sus arreos. Las regiones más afectadas son las manos, antebrazos, y piernas $^{6}$. Las personas que trabajan con ganado vacuno pueden adquirir $S$. scabiei var bovis, que produce lesiones pápulo-vesiculares pruriginosas, ubicadas en zonas de contactos con el animal, especialmente los brazos ${ }^{12}$.

\begin{tabular}{|c|c|c|}
\hline Familia & Ácaro & Hospederos \\
\hline Sarcoptidae & $\begin{array}{l}\text { Sarcoptes scabiei var bovis } \\
\text { Sarcoptes scabiei var canis } \\
\text { Sarcoptes scabiei var equis } \\
\text { Sarcoptes scabiei var ovis } \\
\text { Sarcoptes scabiei var suis } \\
\text { Notoedres cati } \\
\text { Trixacarus caviae }\end{array}$ & $\begin{array}{l}\text { Vacunos } \\
\text { Perro } \\
\text { Caballos } \\
\text { Ovejas } \\
\text { Cerdo } \\
\text { Gatos, felinos, perros, conejos } \\
\text { Roedores }\end{array}$ \\
\hline Psoroptidae & Otodectes cynotis & $\begin{array}{l}\text { Conejos, gatos, hurones, } \\
\text { perros y ratas }\end{array}$ \\
\hline Cheyletellidae & $\begin{array}{l}\text { Cheyletiella blakei } \\
\text { Cheyletiella parasitovorax } \\
\text { Cheyletiella yasguri }\end{array}$ & $\begin{array}{l}\text { Gatos } \\
\text { Conejos y gatos } \\
\text { Perros y gatos }\end{array}$ \\
\hline Macronyssidae & $\begin{array}{l}\text { Ornithonyssus bacoti } \\
\text { Ornithonyssus bursa } \\
\text { Ophionyssus natricis } \\
\text { Ornithonyssus sylviarum }\end{array}$ & $\begin{array}{l}\text { Ratas y ratones } \\
\text { Aves } \\
\text { Reptiles } \\
\text { Aves y ratas }\end{array}$ \\
\hline Dermanyssidae & $\begin{array}{l}\text { Dermanyssus avium } \\
\text { Dermanyssus gallinae } \\
\text { Liponyssoides sanguineus }\end{array}$ & $\begin{array}{l}\text { Aves } \\
\text { Aves } \\
\text { Ratones }\end{array}$ \\
\hline Trombiculidae & $\begin{array}{l}\text { Aconamacarus } \\
\text { Blankaartia } \\
\text { Eutrombicula } \\
\text { Euschoengastia } \\
\text { Neotrombicula } \\
\text { Siseca }\end{array}$ & $\begin{array}{l}\text { Las larvas son parásitos, las } \\
\text { ninfas y adultos viven libres } \\
\text { en el ambiente }\end{array}$ \\
\hline
\end{tabular}

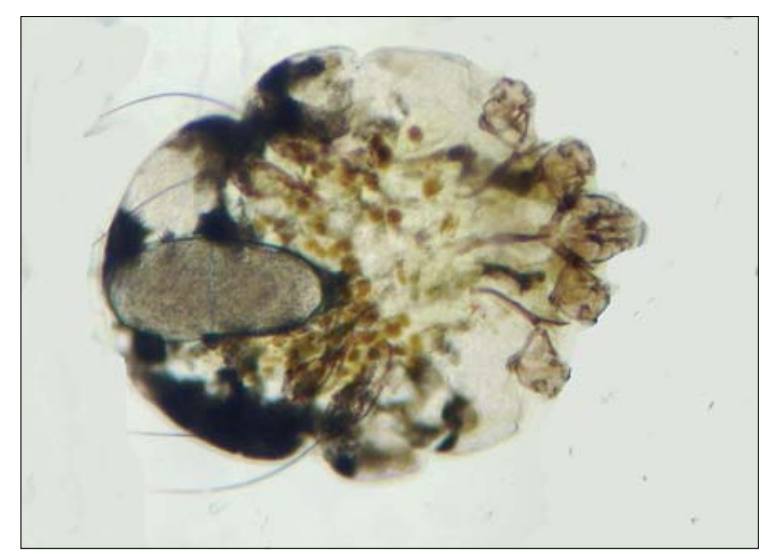

Figura 1. Hembra de Sarcoptes scabiei var canis.
El tratamiento de los animales infestados se realiza con acaricidas, en casos seleccionados con ivermectina, lo que debe ser consultado previamente, por el riesgo de muerte súbita que se asocia a este medicamento. En el hombre el tratamiento es sintomático la mayoría de las veces ${ }^{9,12}$. 


\section{Cheyletiella}

Pertenece a la familia Cheyletiellidae, género Cheyletiella. Es una ectoparasitosis de distribución mundial. Se caracterizan por tener en cada palpo una garra dirigida hacia las piezas bucales y sus patas terminadas en una doble hilera de pelos en vez de ventosas ${ }^{2}$.

\begin{tabular}{|c|c|c|}
\hline Familia & Vector & Agentes \\
\hline \multirow[t]{2}{*}{ Macronyssidae } & Ornithonyssus bacoti & $\begin{array}{l}\text { Bartonella sp } \\
\text { Borrelia burgdorferi } \\
\text { Borrelia recurrentis } \\
\text { Coxiella burnetti } \\
\text { Elleipsisoma tromsoni (roedores) } \\
\text { Hantavirus } \\
\text { Hepatozoon sp (roedores) } \\
\text { Litomosoides carinii (roedores) } \\
\text { Rickettsia akari } \\
\text { Rickettsia prowasekii } \\
\text { Trypanosoma cruzi } \\
\text { Yersinia pestis } \\
\text { Virus coxsackie } \\
\text { Virus de la encefalitis de San Luis } \\
\text { Virus de la encefalitis equina del oeste } \\
\text { Virus Langat }\end{array}$ \\
\hline & $\begin{array}{l}\text { Ornithonyssus sylviarum } \\
\text { Ornithonyssus bursa }\end{array}$ & $\begin{array}{l}\text { Virus de la encefalitis de San Luis } \\
\text { Virus de la encefalitis equina del oeste } \\
\text { Virus de la encefalitis equina del oeste } \\
\text { Coxiella burnetti }\end{array}$ \\
\hline \multirow[t]{2}{*}{ Dermanyssidae } & Dermanyssus gallinae & $\begin{array}{l}\text { Borrelia burgdorferi } \\
\text { Borrelia anserina (aves) } \\
\text { Coxiella burnetti } \\
\text { Erysipelothrix rhusiopathiae } \\
\text { Hantavirus } \\
\text { Listeria monocytogenes } \\
\text { Pasteurella multocida } \\
\text { Salmonella gallinarum } \\
\text { Salmonella enteritidis } \\
\text { Rickettsia sp } \\
\text { Virus de la encefalitis de San Luis } \\
\text { Virus de la encefalitis equina del oeste } \\
\text { Virus de la encefalitis equina venezolana } \\
\text { Virus del Nilo occidental }\end{array}$ \\
\hline & Liponyssoides sanguineus & $\begin{array}{l}\text { Rickettsia akari } \\
\text { Coxiella burnetti }\end{array}$ \\
\hline Trombiculidae & Neotrombicula & $\begin{array}{l}\text { Anaplasma phagocytophilum } \\
\text { Borrelia burgdorferi } \\
\text { Orientia tsutsugamushi }\end{array}$ \\
\hline
\end{tabular}
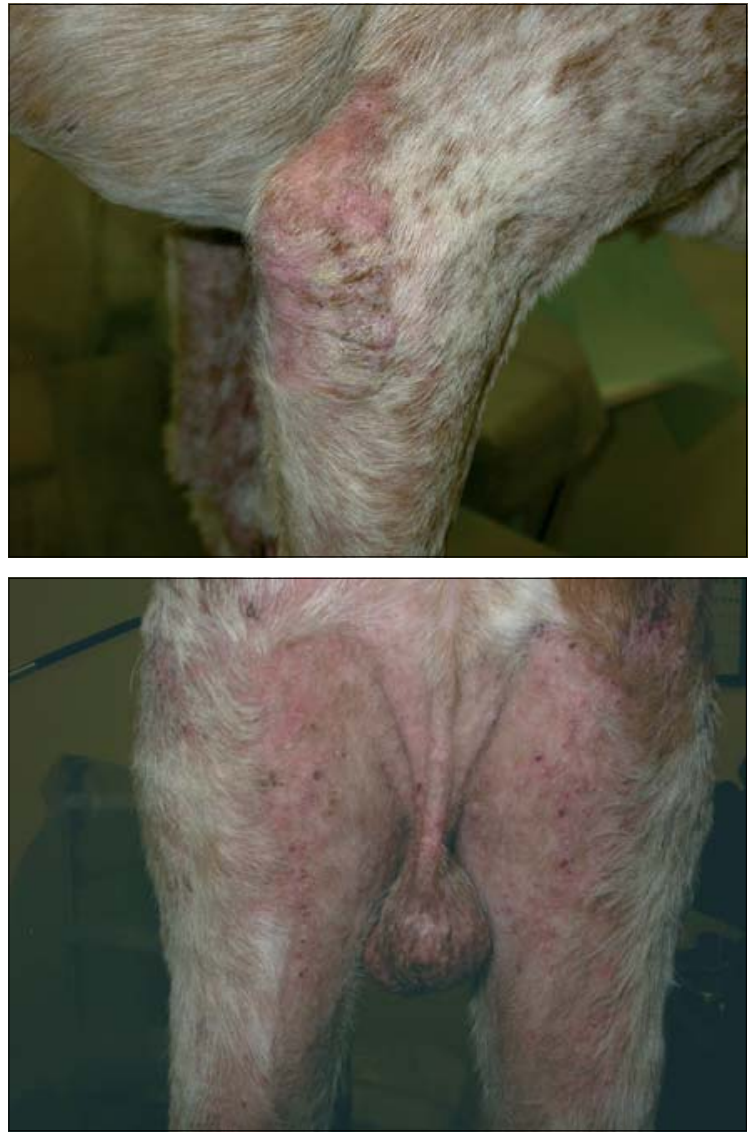

Figuras 2 y 3. Manifestaciones de sarna sarcóptica en perro.

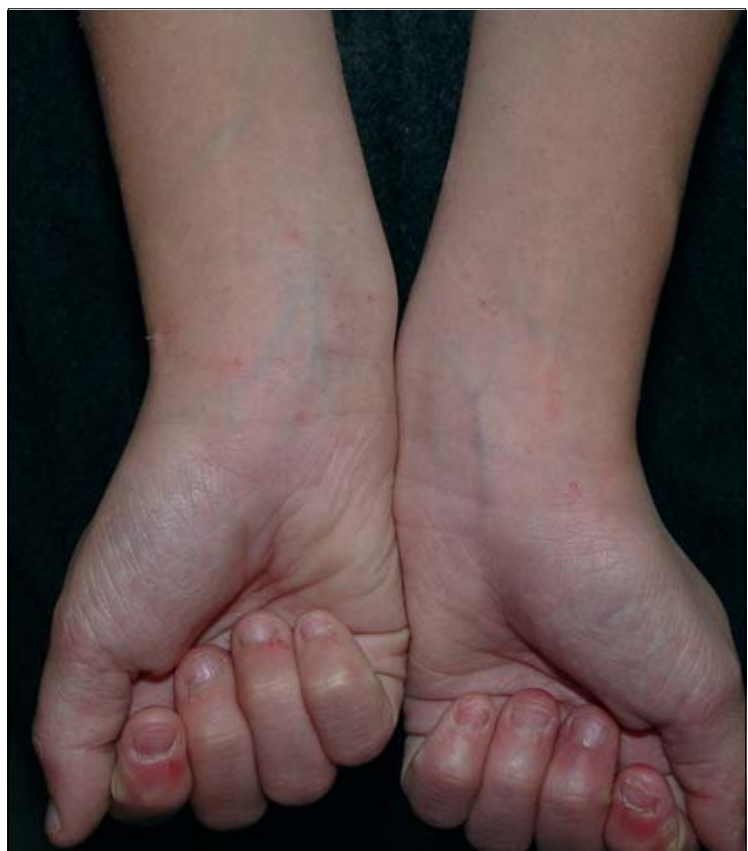

Figura 4. Lesiones de sarna sarcóptica en humanos. 
Fue descrita como causa de dermatitis en el hombre por primera vez en el año 1918 en Copenhague. En animales produce una dermatitis muy contagiosa, exfoliativa, no supurativa, lo que se ha denominado "caspa caminante", debido a que los ácaros trasladan consigo trozos, producto de la descamación que producen. Se encuentra en la placa de queratina de la epidermis, alimentándose en la superficie de detritus y ocasionalmente de linfa ${ }^{13}$.

El ácaro presenta un ciclo que comprende los estadios de huevo, larva, ninfa y adulto; el desarrollo completo demora 35 días. Los huevos se adhieren fuertemente al pelo por bandas fibrilares. Las ninfas, larvas y el macho adulto sobreviven dos días en el ambiente y la hembra adulta 10 días. Mide $0,4 \mathrm{~mm}$ de largo y $0,3 \mathrm{~mm}$ de ancho. Los huevos que se mantienen adheridos al pelaje del animal contribuyen a la reinfestación, transmitiéndose entre ellos por pulgas, piojos o moscas. Se encuentra en perros, gatos, conejos y en forma ocasional en el hombre. En casas con animales infestados con Cheyletiella, $\sim 20 \%$ de los dueños puede contagiarse, siendo posible de encontrar en pisos y alfombras ${ }^{2,13}$.

Hay tres especies de Cheyletiella: C. yasguri que se encuentra en perros y gatos, $C$. blakei en gatos y $C$. parasitovorax en gatos y conejos. En perros y gatos la infestación es, la mayoría de las veces, asintomática; en ocasiones causa prurito. La forma patognomónica se observa en el dorso de los animales con una dermatitis con caspa seca; en casos más graves presenta excoriaciones y zonas alopécicas. En gatos puede producir una dermatitis miliar. En cachorros la infestación generalmente es sintomática, en tanto que en perros adultos y gatos es asintomática ${ }^{14}$.

En el hombre produce lesiones pruriginosas, papulares, pápulo-vesiculares, equimosis urticariales, erupciones vesiculo-bulosas o excoriaciones, en zonas que han estado en contacto con la mascota infestada. La presencia de lesiones eritematosas con una costra central es sugerente de cheiletielosis. En infestaciones de larga evolución, puede encontrarse en la cara. Generalmente son autolimitadas, duran entre 3 y 6 semanas ${ }^{15}$. En hospederos inmunocomprometidos están descritas manifestaciones sistémicas con eosinofilia ${ }^{16}$. Es más frecuente en niños, veterinarios y granjeros ${ }^{17}$.

El diagnóstico se realiza por un raspado de la zona afectada o usando cintas adhesivas que se pegan a un portaobjetos y la observación al microscopio en busca del ácaro o sus huevos. Es posible de visualizar en exámenes copro-parasitológicos, ya que son ingeridos con frecuencia. En el hombre es difícil de encontrar; sin embargo, al aspirar las áreas donde descansan las mascotas y efectuar un examen de flotación del polvo, puede encontrarse ácaros. Los ácaros poseen pelos que atrapan el aire y les permite flotar libremente en el agua ${ }^{2}$.

Como vector de enfermedades C. parasitovorax transmite el virus mixoma de los conejos ${ }^{13}$.

El tratamiento comprende el aseo de la vivienda, tratamiento de las mascotas con permetrina o piretroides; en casos seleccionados o de fracaso de tratamiento ivermectina. En el hombre el tratamiento es sintomático ${ }^{18}$.

\section{Notoedres cati}

Es un ácaro que pertenece a la familia Sarcoptidae con un ciclo de vida similar a S. scabiei. Existen más de 20 especies, la mayoría son ectoparásitos de murciélagos tropicales.

Notoedres cati afecta a gatos, felinos salvajes, civetas, mapaches, coatíes y ocasionalmente al perro y al hombre. Se caracteriza por poseer estriaciones dorsales en forma de anillos concéntricos. El ciclo completo lo realiza en el hospedero y dura 17 días $^{13}$.

Las ninfas y larvas se movilizan libremente por la piel, sobreviven por un breve período en el ambiente. En gatos produce un cuadro muy pruriginoso que se inicia en la zona auricular y rápidamente se disemina a la cara, cuello, párpados y patas; puede haber lesiones perineales. Inicialmente hay una lesión macular, con eritema, alopecia, zonas costrosas y adenopatías regionales. En animales silvestres puede causar la muerte $^{19}$. En el hombre, ocasiona un cuadro similar a la escabiosis, que es autolimitado después de unas semanas de evolución.

El diagnóstico en el animal se realiza por raspado de la piel afectada y visualización del ácaro. El tratamiento es con piretroides o permetrinas del animal afectado y tratamiento sintomático en el hombre. No es vector de enfermedades zoonóticas ${ }^{2,7}$.

\section{Otodectes cynotis}

Conocido como el ácaro de la oreja. Pertenece a la familia Psoroptidae. Afecta a conejos, gatos, hurones, perros y ratas. Se alimenta de detritus del conducto auditivo externo, donde produce una reacción de hipersensibilidad secundaria a proteínas presentes en la saliva. Puede sobrevivir en el ambiente hasta 12 días $^{20}$.

En animales menores es el agente que ocasiona $\sim 30 \%$ de las otitis externas, denominadas oto-acariasis. Se distribuye en la cabeza, canal vertical y horizontal, con eritema, lesiones con costras rojizas, pruriginosas y exudado. En conejos puede extenderse a otras zonas como extremidades y área genital, con enrojecimiento y formación de costras. Afecta con mayor frecuencia a cachorros. Las lesiones se sobreinfectan con agentes bacterianos y fúngicos.

Existen pocos reportes de infestación en humanos, 
donde ocasiona lesiones papulares pruriginosas, localizadas en las zonas de contacto con la mascota infestada.

El tratamiento en animales es con acaricidas aplicados tópicamente $\mathrm{y}$, en algunos casos, ivermectina. En el hombre el tratamiento es sintomático. No es vector de enfermedades zoonóticas ${ }^{1,13}$.

\section{Neotrombicula autumnalis}

A diferencia de otros ácaros, parasita sólo en su estado larval. Pertenece a la familia Trombiculidae. Se encuentra con mayor frecuencia en Europa Central, en lugares con una altura de 3.000 metros, restringido a parques y jardines. Es abundante en verano y otoño.

El ciclo de vida se inicia con huevos que son depositados en el suelo; la larva emerge a los 10 días. Mide 0,4 por $0,2 \mathrm{~mm}$ y es de color rojo anaranjado. Se alimenta de animales de sangre caliente, entre los que se incluye el hombre, por un período de 2 a 10 días. Utiliza unos quelíceros que inyectan enzimas líticas en las capas superficiales de la dermis e ingiere las células digeridas, no son hematófagas. Al cabo de este período vuelve al suelo para continuar su desarrollo a ninfa y adulto, alimentándose de plantas y pequeños insec$\operatorname{tos}^{21}$.

Los perros y roedores son los animales infestados con mayor frecuencia pero puede afectar a aves y reptiles. Los campesinos que trabajan a pie descalzo están expuestos a un mayor riesgo de adquirir esta larva que se localiza en las rodillas, fosa poplítea, región antecubital y pie. La expoliación de sangre es dolorosa, con inflamación de la piel y prurito intenso, que persiste aún después de que la larva abandona al hospedero. En animales puede causar compromiso neurológico con paresia de extremidades posteriores, astenia y claudicación.

Es un vector de Anaplasma phagocytophilum, que se ha detectado hasta en $10 \%$ de las larvas, previo al contacto con el hospedero, lo que sugiere una transmisión transovárica. Se asocia a la transmisión de Borrelia burgdorferi ${ }^{22}$.

\section{Ácaros de aves}

\section{Dermanyssus gallinae}

Llamado el ácaro rojo de las aves o "piojillo de los gallineros". Fue descrito por primera vez el año 1778 por de Geer. El primer caso de infestación en humanos data del año 1809; en nuestro país la primera descripción es del año $1959^{23}$. Pertenece a la familia Dermanyssidae. Existen tres especies: Dermanyssus gallinae, D. americanus o ácaro de las aves americano y D. hirundinis.
Es frecuente en climas templados alrededor del mundo. Se encuentra en aves de corral, canarios, halcones, pavos, palomas y aves silvestres. Afecta a caballos, gatos, jerbos, perros y al hombre, cuando está en contacto con aves de corral ${ }^{24}$. La infestación es más frecuente en primavera y verano ${ }^{25}$.

Este ácaro es hematófago. La hembra mide 0,7 por $0,4 \mathrm{~mm}$ y el macho 0,6 por $0,3 \mathrm{~mm}$. Es de color amarillo café sin alimentar y de color rojo o negro cuando está saciado. Los huevos se encuentran cerca de los nidos de las aves. La larva no se alimenta, la ninfa y los adultos se alimentan por lo general de noche, de día vuelve a su lugar habitual en nidos de gallinas o hendiduras en el suelo. Los adultos pueden permanecer sin alimentarse en el ambiente hasta por 34 semanas. En los gallineros puede encontrarse $D$. gallinae hasta seis meses después de removidas las aves ${ }^{25}$.

En aves de corral ocasiona significativas pérdidas económicas por anemia, disminución de la producción de huevos, pérdida de peso y mortalidad asociada ${ }^{24}$. En perros y gatos produce eritema, pápulas y costras especialmente en la cabeza, dorso y extremidades ${ }^{26}$. En el hombre produce lesiones similares a una sarna, de tipo papular pruriginosa o erupciones urticariales, con prurito nocturno. Respeta las zonas de la cara, interdigital y genital. Han sido descritos brotes intrahospitalarios en relación a contacto con nidos de palomas infestadas y casos de otitis externa en trabajadores avícolas $^{28-32}$.

Dermanyssus gallinae puede ser un potencial vector para Salmonella gallinarum y S. enteritidis, que adquiere por contacto cuticular o por alimentación con sangre infectada. La bacteria se multiplica y se transmite a la próxima generación por vía trans-estadial, con retransmisión a otras aves por picaduras ${ }^{33}$.

De este ácaro se ha aislado B. burgdorferi, $B$. anserina, agente de la espiroquetosis de las aves, Listeria monocytogenes, Erysipelothrix rhusiopathiae y los virus de la encefalitis equina del oeste, encefalitis de San Luis, encefalitis equina venezolana y virus del Nilo Occidental ${ }^{24,34-36}$. En algunos casos se ha demostrado la transmisión del agente a las aves, no así del ácaro al hombre ${ }^{25}$.

El diagnóstico es posible de hacer con su visualización. El estudio histológico muestra infiltración eosinofílica perivascular de la dermis superficial. El tratamiento se realiza con la aplicación de acaricidas en el ambiente y del animal infestado y manejo sintomático en el caso del hombre.

\section{Ornithonyssus sylviarium}

Pertenece a la familia Macronyssidae. Realiza su ciclo completo en las aves, donde permanece en el plumaje. Afecta con mayor frecuencia a pollos, pavos 
y ocasionalmente al hombre, reptiles y roedores. Desarrolla su ciclo vital en siete días. Sobrevive hasta 3 ó 4 semanas fuera del hospedero ${ }^{34}$.

En el hombre produce lesiones papulares pruriginosas, papulo-urticariales o papulo-vesiculares. Puede afectar las regiones interdigitales. Accede desde sitios vecinos, de nidos de aves abandonados, a través de los sistemas de aire acondicionado o por hendiduras. Se ha reportado casos en humanos en E.U.A y Japón. En el roedor causa fisuras y costras alrededor de la cloaca.

El tratamiento consiste en la erradicación de los nidos de aves abandonados y la eliminación o tratamiento del animal afectado. Es considerado un vector para el virus de la encefalitis de San Luis y encefalitis equina del oeste ${ }^{2,36}$.

\section{Ornithonyssus bursa}

Pertenece a la familia Macronyssidae. Se encuentra en zonas tropicales y subtropicales. Afecta a pollos, pavos, paloma, gorriones y otras aves. Es hematófago. Vive en los nidos de las aves donde desarrolla su ciclo vital. No sobrevive más de 10 días fuera del hospedero habitual $^{2}$. Puede migrar a casas desde nidos abandonados o de corrales de aves. Es vector del virus de la encefalitis equina del oeste y de Coxiella burnetti ${ }^{36}$.

\section{Ácaros de roedores}

Entre los ácaros que parasitan a roedores se encuentran las especies Ornithonyssus, Liponyssoides sanguineus, Echinolaelaps echidninus y Trixascarus caviae.

\section{Ornithonyssus bacoti}

Pertenece a la familia Macronyssidae. Las primeras descripciones de dermatitis por este agente fueron el año 1913 en Australia, 1923 en E.U.A y 1931 en Alemania. Se trata de una afección universal con casos descritos en varios países, a excepción de los continentes helados. Existen tres especies de Ornithonyssus: $O$. bacoti cuyo hospedero principal es los roedores, $O$. bursa y O. sylviarum que ocasionalmente afectan a roedores ${ }^{2,3}$.

Ornithonyssus bacoti o ácaro tropical de los ratones, se encuentra con mayor frecuencia en climas tropicales y templados. Se desarrolla mejor en temperaturas entre 24 y $26^{\circ} \mathrm{C}$, con una humedad de $47 \%$. Las picaduras en el hombre se reportan con una mayor frecuencia en primavera ${ }^{37}$.

Es un ácaro hematófago, se alimenta por succión mediante un aparato bucal que tiene dos quelíceros terminales. El extremo proximal que permite la succión de sangre es de tipo tubular con un diámetro de $6 \mu \mathrm{m}$, similar al de un vaso sanguíneo. Ornithonyssus bacoti pone los huevos en madrigueras, nidos o jaulas de roedores, jerbos y pequeños marsupiales ${ }^{38}$.

En el hombre ocasiona una dermatitis pruriginosa ${ }^{38}$. No existía información en nuestro país de dermatitis asociadas a $O$. bacoti hasta noviembre del año 2007, donde se identificó en un brote que afectó a varios médicos que compartían la residencia en un hospital de construcción antigua (Juliet $\mathrm{C}$, datos no publicados) y en el caso de una paciente que consultó por lesiones pruriginosas en extremidades, con el antecedente de sentir roedores en el techo de su casa y la identificación del ácaro que la paciente llevó a la consulta (Saavedra T, datos no publicados) (Figura 5).

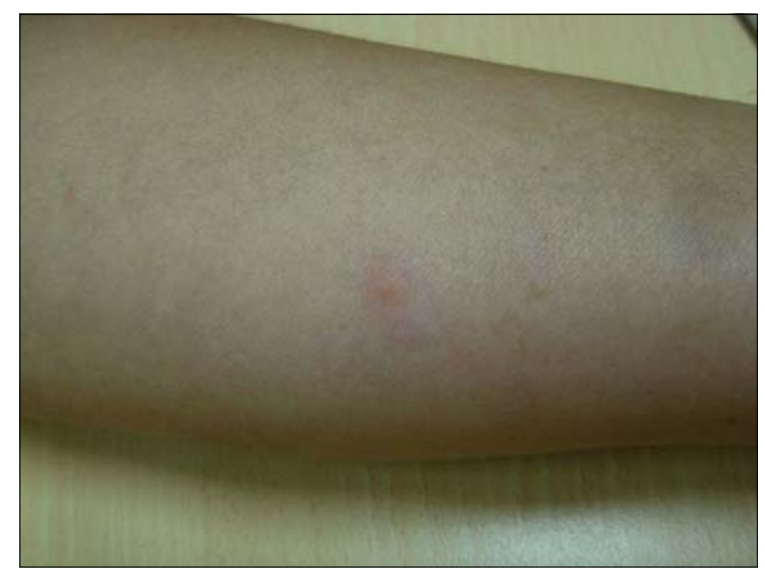

Figura 5. Lesión papular por picadura de Ornithonyssus bacoti.
El ciclo biológico comprende los siguientes estadios: huevo, larva, ninfa y adulto. La hembra grávida se alimenta de sangre y después de ello, deja al hospedero para digerir por dos a tres días la sangre expoliada. Al término de este período pone entre uno y 12 huevos, en las madrigueras o nidos de roedores; en caso de animales de laboratorio en grietas o junturas de las jaulas. De los huevos eclosionan larvas en un día y medio, que poseen tres pares de patas y no se alimentan. La larva pasa a protoninfa con cuatro pares de patas, se alimenta de sangre y posteriormente pasa a deutoninfa, que no se alimenta y es la que se transforma en adulto en un plazo de 24 horas. Ocasionalmente se describe un ciclo reproductivo partenogenético ${ }^{39}$. El ciclo dura entre 11 y 16 días, pudiendo generar grandes poblaciones en corto tiempo ${ }^{2}$.

Bajo condiciones ambientales adversas, la protoninfa es capaz de sobrevivir hasta 43 días sin alimentarse, la forma adulta hasta 63 días. El promedio de vida de la hembra es de seis meses y del macho 1, 5- 2, 5 meses. 
Figura 6. Ornithonyssus bacoti. Visión con aumento 100X.
El macho se alimenta de sangre, pero en menor cantidad que la hembra. Generalmente pica de noche y a animales de sangre caliente. No excava la piel, a diferencia de $S$. scabie $^{40}$.

Es de tamaño pequeño, no visible a simple vista si no se han alimentado. Cuando está ingurgitado con sangre aumenta su tamaño al doble, lo que facilita su visión. La hembra mide entre 0,7 y 1, 4 mm, el macho es más pequeño, mide 0,4 a $0,5 \mathrm{~mm}$. La hembra es de color grisáceo, muy activa cuando está sin alimentar. Después de la ingestión de sangre es de color rojizo y de movimientos lentos (Figura 6).

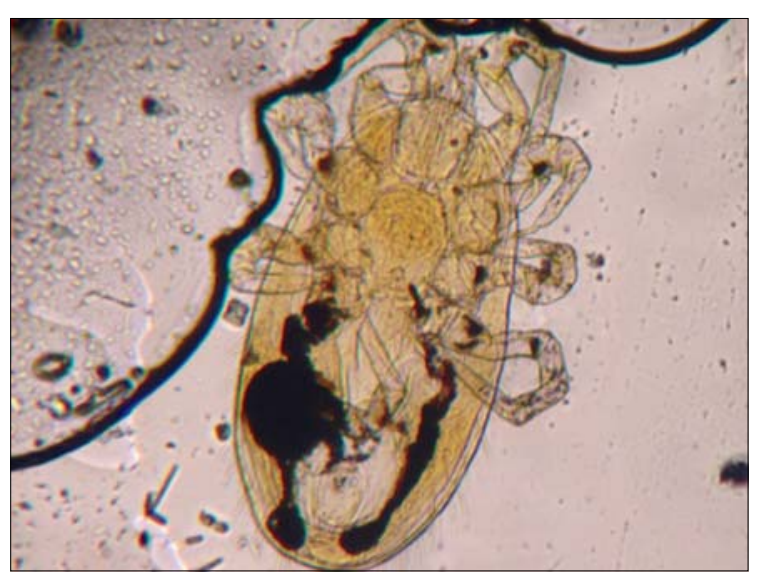

Ornithonyssus bacoti se asocia particularmente a la rata negra de los techos (Rattus rattus), pero también puede encontrarse en ratas ( $R$. norvegicus), ratón doméstico (Mus musculus), hamsters (Mesocricetus auratus), jerbos (Meriones unguiculatus) y otras 10 especies de mamíferos pequeños. Ha sido posible su identificación en momias de cuyes en el descubrimiento arqueológico de El Yaral, al sur de Perú ${ }^{41}$. Invade las casas cuando se hacen campañas de eliminación de roedores, que no incluyen la supresión de los artrópo$\operatorname{dos}^{2}$.

En mascotas y roedores de laboratorio, la picadura de $O$. bacoti produce anemia, debilidad, disminución de la capacidad reproductiva e incluso muerte del ani$\mathrm{mal}^{40,42}$. En el hombre la picadura es dolorosa y causa irritación con una dermatitis localizada, lo que genera un intenso prurito. En la zona afectada, se aprecian pápulas de 3 a $4 \mathrm{~mm}$ de diámetro; raramente ocasiona vesículas, máculas o zonas hemorrágicas, que se asocia con mayor frecuencia a una picadura por $O$. bursa. Las lesiones se localizan en zonas accesibles del cuerpo; las zonas cubiertas están protegidas. La marca de la picadura puede permanecer hasta por tres semanas.
Es posible encontrarla en la ropa y puede ser transmitido por fomites. Es más fácil de visualizar en el ambiente que en el hospedero, especialmente si la superficie es clara ${ }^{38}$.

Los niños son más susceptibles a la infestación por el hábito de sentarse a jugar en alfombras, piso o suelo. Los trabajadores de laboratorios o de tienda de mascotas en contacto con roedores tienen un mayor riesgo de picadura. Los casos, por lo general, se presentan en brotes con un nexo epidemiológico, asociados a la presencia de roedores ${ }^{37}$.

En estudios histológicos de lesiones se ha encontrado infiltración linfoplasmocitaria con la presencia de eosinófilos.

El diagnóstico se considera en casos de hallazgo del ácaro y/o presencia de roedores en el ambiente. Se confirma por sus características morfológicas y tamaño; puede verse en preparaciones al microscopio corriente, en lactofenol o a microscopia electrónica. La mayoría de las veces se captura a la hembra, que ingurgitada puede alcanzar el tamaño de $1 \mathrm{~cm}$, lo que facilita su visualización ${ }^{43}$. Morfológicamente es similar a D. gallinae y $O$. sylviarum, se diferencia por presentar gran cantidad de pelos en la zona abdominal, un ápice caudal grueso y un escudo ovo genital con un ano en posición craneal ${ }^{39}$. Los principales diagnósti$\cos$ diferenciales son: escabiosis, acarosis ocasionadas por otros animales, pulicosis, prúrigo insectario y pediculosis corporis entre otros.

En forma experimental en roedores, se ha demostrado que puede ser vector para B. burgdorferi, C. burnetti, Rickettsia prowasekii (agente del tifus exantemático epidémico), plaga, fiebre recurrente, hantavirus, virus coxsackie, virus de encefalitis de San Luis, encefalitis equina del oeste y del virus Langat (agente de encefalitis por picadura de garrapatas) ${ }^{36,44-46}$.

Rickettsia akari (akari, nombre griego de ácaro), agente de la ricketsiosis pustulosa humana (rickettsialpox), se transmite en Ornithonyssus por pasaje transovárico, con una menor eficacia comparado con Liponyssoides sanguineus. Esta enfermedad fue descrita por primera vez en Nueva York el año 1946. Se caracteriza por la aparición, a las 24 a 48 horas de ocurrida la picadura, de una lesión primaria pápulovesicular en el sitio de inoculación, con adenopatías regionales y posterior formación de escara, que mejora en tres a cuatro semanas. Una semana después de la lesión primaria, el paciente comienza con fiebre alta, decaimiento y cefalea. Entre tres a siete días del inicio de la fiebre, aparecen lesiones maculares, papulares y vesiculares diseminadas, que pueden acompañarse de enantema, dolor abdominal, disfagia, fotofobia, inyección conjuntival y rinorrea. Al examen físico puede haber esplenomegalia. El exantema desaparece, por lo 
general, a la semana. En el hemograma se encuentra leucopenia en $\sim 75 \%$ de los casos, linfocitosis y desviación a izquierda. El paciente se recupera sin complicaciones en una semana, aun sin tratamiento. El decaimiento y la cefalea pueden mantenerse por dos semanas. El diagnóstico diferencial es con dos agentes de bioterrorismo: ántrax y viruela. El tratamiento de elección es doxiciclina o tetraciclina ${ }^{47,48}$.

Recientemente se detectó la presencia de Bartonella sp en ratas de Egipto. Ornithonyssus bacoti es el hospedero intermediario de la filaria de los roedores llamada Litomosoides carinii, que no es patógena para el hombre ${ }^{48}$. En condiciones experimentales es un vector mecánico para Trypanosoma cruzi $^{36}$.

El tratamiento de la picadura del ácaro de la rata es sintomático, con antialérgicos y corticosteroides tópicos en los casos más graves. No requiere uso de acaricida.

La prevención y control se realiza con la desratización del lugar donde se encuentren roedores, junto con un aseo prolijo de las viviendas. Al eliminar los roedores, los ácaros buscan nuevas fuentes de alimentación, por lo que se debe aplicar insecticidas, una vez que se desratiza. Especial precaución debe tenerse en lugares abandonados o edificios antiguos.

\section{Liponyssoides sanguineus}

Llamado Allodermanyssus sanguineus. Pertenece a la familia Dermanyssidae junto a $D$. gallinae. Se encuentra en el norte de África, Asia, Europa y E.U.A. Su presencia ha sido descrita en el país.

El ciclo es similar a D. gallinae, demora de 18 a 23 días, puede sobrevivir en el ambiente hasta 51 días sin alimentarse. Liponyssoides abunda en asociación con ratones $M$. musculus, pero cuando es necesario se alimenta de otros roedores y eventualmente del hombre. En animales ocasiona anemia, debilidad, irritación y muerte. En el hombre ocasiona una dermatitis pruriginosa $^{2}$.

Transmite $R$. akari tanto por vía trans-ovárica como trans-estadial, por lo que es el vector más importante de este agente. En zonas del noroeste de E.U.A. la ricketsiosis pustulosa fue un importante problema de salud pública, considerada una zoonosis urbana ligada a la sobrepoblación de roedores. En la actualidad la incidencia de esta enfermedad ha disminuido, por un mejor control de los roedores ${ }^{49}$.

Es un vector para $C$. burnetti, con transmisión demostrada entre aves y roedores ${ }^{36}$.

\section{Echinolaelaps echidninus}

Llamado ácaro espinoso del ratón. Pertenece a la familia Gamasidae. Se ha detectado su presencia en roedores de Argentina, Brasil, África y Asia. La pica- dura es pruriginosa, no hay casos descritos en humanos. Es el hospedero intermediario de un histoparásito llamado Hepatozoon muris y H. perniciosum. No hay evidencias de que sea vector de agentes patógenos para el hombre ${ }^{36}$.

\section{Trixacarus caviae}

Es un ácaro parecido a S. scabiei, pero de menor tamaño. Tiene varias diferencias morfológicas como la localización dorsal del ano en el macho y ventral en la hembra, con una sola saeta y espina dorsal.

Fue descrito por primera vez el año 1972, como una nueva especie causante de sarna en conejillo de indias en Oxford, Inglaterra y posteriormente en E.U.A.

En estos animales ocasiona lesiones pruriginosas que afectan el tronco, dorso y hombros. La zona comprometida puede estar reseca o húmeda, con costras y el pelaje es fácilmente removible. Se puede asociar a abortos, infertilidad, convulsiones y muerte del animal. El período de incubación oscila entre 10 y 50 días. Existen portadores asintomáticos, condición que cambia a sintomática en caso de embarazo, traslado del animal u otros factores estresantes. La infestación se adquiere precozmente post nacimiento, las lesiones aparecen a las 72 horas de vida, el eritema a la tercera y cuarta semana. Este ácaro no es capaz de sobrevivir en el medio ambiente.

En el hombre causa lesiones parecidas a la sarna, en manos y brazos, y son pruriginosas. Es más frecuente en niños.

El diagnóstico se realiza con raspado de piel o uso de cinta adhesiva. El tratamiento consiste en la aplicación de acaricidas tipo piretrinas en el animal y antialérgicos en el hombre. No es vector de enfermedades zoonóticas $^{50,51}$.

\section{Ácaros de reptiles}

\section{Ophionyssus natricis}

Pertenece a la familia Macronyssidae, es hematófago. Es la ectoparasitosis más frecuente de los reptiles; se ubica en las zonas protegidas bajo las escamas, detrás de los ojos, comisuras labiales y pliegues cutáneos de la zona pericloacal. Es posible de encontrar en las jaulas o en los alrededores en grietas o hendiduras. Ocasiona incomodidad del animal, anemia, anorexia, depresión, dificultad en la muda e incluso la muerte. En el hombre produce lesiones papulares, pruriginosas, en zonas que han estado en contacto con reptiles.

El tratamiento del reptil afectado es con acaricidas o ivermectina; en el hombre el tratamiento es sintomático. 
No es vector de enfermedades transmisibles al hombre. Es un hospedero intermediario de algunos agentes parasitarios para el reptil ${ }^{7,52}$.

\section{Conclusiones}

Los ácaros de animales dan manifestaciones clínicas en humanos en forma excepcional. Las lesiones que producen son generalmente papulares, pruriginosas y autolimitadas, en zonas descubiertas que han estado en contacto con los ácaros. Se debe sospechar cuando hay antecedentes de contacto con mascotas o animales silvestres o la permanencia en el ambiente de estos hospederos.

Algunos de estos ácaros son vectores de enfermedades que pueden afectar tanto al hombre como a los animales. El tratamiento es el manejo ambiental con acaricidas, tratamiento tópico del animal cuando corresponda y uso de antialérgicos en caso de lesiones en el hombre. El cuidado responsable de mascotas y el conocimiento de estas patologías, son las medidas más importantes de prevención.

\section{Resumen}

Los ácaros de animales (acariasis) pueden transmitirse en forma accidental al hombre al estar en contacto con ellos, produciendo lesiones características (pápulas o vesículas) y ocasionando una dermatitis pruriginosa (acarosis). Existen diversas especies de ácaros, que se encuentran en perros, gatos, roedores, aves y reptiles. Los ácaros hematófagos o los que se alimentan de linfa tienen el potencial de transmitir importantes agentes zoonóticos. La presencia de lesiones sin una etiología clara y el antecedente de contacto con animales, tanto mascotas como animales silvestres, ayudan a plantear esta etiología. El diagnóstico se realiza con la visualización del ácaro, morfología y tipo de hospedero animal. El conocimiento de estas acarosis y el control responsable de mascotas y animales, son las principales medidas de prevención.

\section{Referencias}

1.- Krauss H, Weber A, Apple M, Enders B, Isenberg H D, Schiefer HG Chapter 4. Parasitic zoonoses. Zoonoses caused by mites. Zoonoses infectious disease transmissible from animals to humans. $3^{\text {th }}$ ed. ASM Press, Washington, 2003. pp 399-402.

2.- Acha P, Szygres B. Capítulo: Dermatitis por ácaros de origen animal. Zoonosis y enfermedades transmisibles comunes al hombre y a los animales. $3^{\text {a }}$ ed. 2003. Editorial Washington, DC: OPS, OMS. pp 343-7.

3.- Cheng T C. Capítulo: Ácaros. Cheng T C. Parasitología General. Segunda edición 1980. Editorial AC. Madrid. España. pp 751-77.

4.- Díaz J H. The epidemiology, diagnosis, management and prevention of ectoparasitic diseases in travelers. J Travel Med 2006; 13: 100-11.

5.- Steen C J, Carbonaro P A, Schwartz R A. Arthropods in dermatology. J Am Acad Dermatol 2004; 50: 819-42.

6.- Cordero del Campillo M, Rojo F, Martínez A, Sánchez C, Hernández S, Navarrete I, et al. Parasitología Veterinaria. Madrid, España. $1^{\circ}$ Ed. Mc Graw-Hill Interamericana.1999. pp 158-63, 706-8.

7.- Berck W, Pfister K. Mites as a cause of zoonoses in human beings. Wien Klin Wochensch 2006; 118 (Suppl 3): 27-32.

8.- Demis J D. Injurious effects in man induced by animals, Scabies (itch mites). Demis J D, Ed. Clinical Dermatology. 25 Edit. Philadelphia, Lippincot Co 1994; Unit 18-32 (3): 1-6.

9.- Saavedra T, Díaz C, Leiva A, Zapata S. Sarna sarcóptica transmitida a humano. Rev Chil Dermatol 2007; 23: 302-4.

10.- Larsson M H. Evidências epidemiológicas da ocorrência de escabiose, em humanos, causada pelo Sarcoptes scabiei (DeGeer, 1778) var. canis (Bourguignon, 1853). Rev Saúde Públ S Paulo 1978; 12: 333-9.

11.- Abarca K, Jofré L, López J, Lorca L. Pauta técnica de vigilancia de enfermedades transmisibles en pequeños animales de compañía. Disponible en http:// www.vigivet.com/pauta_tecnica.htm/. (accedido 24 de marzo 2008)

12.- Ulmer A, Schanz R, Rocken M, Fierldeck G. A papulovesicular rash in a farmer and his wife. Clin Infect Dis 2007; 45: 352, 395-6.

13.- Curtis C. Current trends in the treatment of Sarcoptes, Cheyletiella and Otodectes mite infestation in dogs and cats. Vet Dermatol 2004; 15: 108-14.

14.- Wagner R, Stallmeister H. Cheyletiella dermatitis in humans, dogs and cats. Br J Dermatol 2000; 143: 110-2.

15.- Cvancara J, Elston D. Bullous eruption in a patient with systemic lupus erythematosus mite dermatitis caused by Cheyletiella. J Am Acad Dermatol 1997; 21: 265-7.

16.- Dobrosavljevic D D, Popovis N K, Radovanics S S. Systemic manifestations of
Cheyletiella infestations in man. Int J Dermatol 2007; 46: 397-9.

17.- Tsianakas P, Polack B, Levyktlotz B, Prost-Squarcioni C. Cheyletiella dermatitis an uncommon cause of vesiculobullous eruption. Ann Dermatol Venereol 2000; 127: 826-8.

18.- Elston D M. What's eating you? Cheyletiella mites. Cutis 2004; 74: 23-4.

19.- Leone F. Canine notoedric mange: a case report. Vet Dermatol 2007; 18: 127-9.

20.- Otranto D, Milillo P, Mesto P, De Caprarris D, Perrucci S, Capelli G. Otodectes cynotis (Acari: Psoroptidae): examination of the survival off the host under natural and laboratory conditions. Exp Appl Acarol 2004; 32: 171-9.

21.- Guarneri F, Pugliese A, Giudice E, Guarneri C, Giannetto S, Guarneri B. Trombiculiasis: clinical contribution. Eur J Dermatol 2005; 15: 495-6.

22.- Siddiqui S, Master Sanker Raj V, Feinberg A N. Visual diagnosis: a 5 -year-old male who has an intensely pruritic maculopapular rash. Pediatr Rev 2009; 30; 26-9.

23.- Schenone H. Dermatitis pruriginosa producida por el ácaro Dermanyssus gallinae (De Geer 1778). Bol Chil Parasitol 1959; 14: $57-8$.

24.- Green B, Sparling J, Sperling M B. What's eating you? Pigeon mite (Dermanyssus gallinae). Cutis 2007; 80: 461-2.

25.- Reed J, Hewitt R, Barrow G I. Mite 
infestation. Br Med J 1966; 6: 622-3.

26.- Haag-Wackernagel D. Parasites from feral pigeons as a health hazard for humans. Ann Applied Biol 2005; 147: 203-10.

27.- Guin J D. Contact arthropod reactions: beware the family cat. Contact Dermatitis 2005; 52: 44-5.

28.- Lucky A W, Sayers P, Argus D, Lucky A. Avian mite bites acquired from a new source-pet gerbils. Arch Dermatol 2001; 137: 167-70.

29.- Baselga E, Crolet BA, Esterly B. Avian mite dermatitis. Pediatrics 1996; 5: 743-5.

30.- Bellanger AP, Bories C, Foulet F, Bretagne S, Bottirel F. Nosocomial dermatitis caused by Dermanyssus gallinae. Infect Control Hosp Epidemiol 2008; 29: 282-3.

31.- Auger P, Nantel J, Meunier N, Harrison R J, Loiselle R, Gyorkos T W. Skin acariasis caused by Dermanyssus gallinae (de Geer): an in hospital outbreak. Can Med Assoc J 1979; 120: 700-3.

32.- Rossiter A. Occupational otitis externa in chicken catchers. J Laryngol Otol 1997; 111: 366-7.

33.- Valiente Moro C, Desloire S, Chauve C, Zenner L. Detection of Salmonella sp in Dermanyssus gallinae using and FTA filter-based polymerase chain reaction. Med Vet Entomol 2007; 21: 148-52.

34.- Chirico J, Eriksson H, Fossum O, Gansson D. The poultry red mite, Dermanyssus gallinae, a potential vector of Erysipelothrix rhusiopathiae causing erisipela in hens. Med
Vet Entomol 2003; 17: 232-4.

35.- Orton D I, Warren L J, Wilkinson J D. Avian mite dermatitis. Clin Exp Dermatol 2000; 25: 129-31.

36.- Valiente Moro C, Chauve C, Zanner L. Vectorial role of some Dermanyssoid mites (Acari, Mesostigmata, Dermanyssoid). Parasite 2005; 12: 99-109.

37.- Beck W, Pfister K. Mites as newly emerging disease pathogens in rodents and human beings. Vet Dermatol 2004; 15 (Suppl 1): 35.

38.- Chung S L, Hwang S U, Kwon S B, Kim D W, Jun J B, Cho B K. Outbreak of rat mite dermatitis in medical students. Int J Dermatol 1998; 37: 591-4.

39.- Engel P M, Welzel J, Maaas M, Schramm U, Wolff $\mathrm{H} \mathrm{H}$. Tropical rat mite dermatitis: case report and review. Clin Infect Dis 1998; 27: $1465-9$.

40.- Baumstark J, Beck W, Hoffman H. Outbreak of tropical rat mite (Ornithonyssus bacoti) dermatitis in a home for disabled persons. Dermatology 2007; 215: 66-8.

41.- Dittmar K. Evaluation of ectoparasites in the guinea pig mummies or El Yaral and Moquequa Valley, in southern Perú. Chungara, Rev Antropol Clin 2000; 32: 123-5.

42.- Creel N B, Crowne M A, Mullan G R. Pet hamsters as a source of rat mite dermatitis. Cutis 2003; 71: 457-61.

43.- Watson J. New building, old parasite: Mesostigmatid mites an ever-present threat to barrier facilities. ILAR J 2008; 49: 303-9.
44.- Pizzi R, Meredith A, Thoday K L, Walker A. Ornithonyssus bacoti infestation on pets in UK. Vet Record 2004; 154: 437-8.

45.- Beck W, Pfister K. Ocurrence of a house infesting tropical rat mite (Ornithonyssus bacoti) on murides and human beings in Munich: 3 cases reported. Wien Klin Wochenschr 2004; 116 (Suppl 4): 65-8. 46.- Reeves W K, Loftis A D, Szumlas D E, Abbassy M M, Helmy I M, Hanafi H A, et al. Rickettsial pathogens in the tropical rat mite Ornithonyssus bacoti (Acari: Macronyssidae) from Egypt rats (Rattus spp). Exp Appl Acarol 2007; 41: 101-7.

47.- Saini R, Pui J C, Burgin S. Rickettsialpox: report of three cases and review. J Am Acad Dermatol 2004; 51: S137-42.

48.- Paddock C D, Zakis S, Koss T, Singleton J, Sumner J W, et al. Rickettsial pox in New York City: a persistent urban zoonosis. Ann NY Acad Sc 2003; 990: 36-44.

49.- Claverie F G, Causapian J, de Guzmán M A, Toledo M G, Salibay C. Parasite biodiversity in Rattus spp caught in wet markets: Southeast Asian J Trop Med Public Health. 2005; 36 (Suppl 4): 146-8.

50.- Ackerman L. Trixacarus caviae infestation in a guinea pig. Can Vet J 1987; 28: 613.

51.- Fuentealba C, Hanna P. Mange induced by Trixacarus caviae in a guinea pig. Can Vet J 1996; 37: 749-50.

52.- Schultz H. Human infestation by Ophionyssus natricis snake mite. Br J Dermatol 1975; 93: 695-7. 